\title{
Pendampingan Pembuatan Bahan Ajar Bagi Guru Sekolah Dasar Islam Terpadu (SDIT) Salsabila Al Muthi'in Berbasis Multimedia dengan Menggunakan Microsoft Power Point
}

\author{
Astika Ayuningtyas ${ }^{1}$, Anton Setiawan H. ${ }^{2}$, Asih Pujiastuti ${ }^{3}$, \\ Nurcahyani Dewi Retnowati ${ }^{4}$, Yuliani Indrianingsih ${ }^{5}$ \\ Program Studi Teknik Informatika \\ Sekolah Tinggi Teknologi Adisutjipto \\ Jl. Janti Blok R Lanud Adisutjipto Yogyakarta \\ ${ }^{1)}$ astika@stta.ac.id, ${ }^{2)} \frac{\text { Anton_s_havahoo.com, }}{{ }^{5)} \text { yulistta@gmail.com }}$
}

\begin{abstract}
Teachers are a very noble profession, because one of the teachers' tasks is to help the intellectual life of the nation. As teachers in their daily lives to educate the nation, requires the support of equipment that can be used in the teaching and learning process in the field that it has. The necessary support material may be hardware and software that can be used to compile teaching materials of interest to learners. Therefore, teachers should have the skills as educators to leverage the kmputer hardware and software correctly to create interactive educational materials in the digital age, one of the multimedia-based teaching materials using Microsoft software Power point. The purpose of teaching didactic materials for teachers is to provide teachers with skills to use the use of Microsoft Power Point to produce interactive documents that may be more interesting for student learning. Thus, the implementation of community service activities with the title "support for the development of educational materials for primary school Teachers ISAM (SDIT) Salsabila Al Muthi'in multimedia through the use of Microsoft Power Point" offers advantages important for improving teachers' skills in the use of information and computer technologies.
\end{abstract}

Keywords : multimedia, teachers, microsoft power point, digital

\section{Abstrak}

Guru merupakan profesi yang sangat mulia, karena salah satu tugas guru yaitu membantu dalam mencerdaskan kehidupan bangsa. Sebagai guru dalam kesehariannya untuk mencerdaskan kehidupan bangsa, membutuhkan adanya peralatan penunjang yang dapat digunakan dalam proses belajar mengajar di bidang yang diampunya. Peralatan penunjang yang dibutuhkan dapat berupa perangkat keras dan perangkat lunak yang dapat dimanfaatkan untuk menyusun bahan ajar yang menarik bagi perserta didiknya. Oleh sebab itu, guru selaku pendidik harus memiliki keterampilan memanfaatkan perangkat keras dan lunak kmputer dengan baik agar dapat membuat bahan ajar yang interaktif di era digital ini, salah satunya bahan ajar yang berbasis multimedia menggunakan perangkat lunak Microsoft Power Point. Tujuan pendampingan pembuatan bahan ajar bagi guru ini adalah memberikan bekal keterampilan bagi guru agar dapat memanfaatkan penggunaan Microsoft Power Point untuk menghasilkan bahan ajar yang interaktif sehingga dapat lebih menarik minat belajar siswasiswi. Dengan demikian, pelaksanaan kegiatan pengabdian kepada masyarakat dengan judul "Pendampingan Pembuatan Bahan Ajar Bagi Guru Sekolah Dasar Islam Terpadu (SDIT) 
Salsabila Al Muthi'in Berbasis Multimedia dengan Menggunakan Microsoft Power Point" memberikan manfaat yang signifikan bagi peningkatan keterampilan guru dalam memanfaatkan teknologi informasi dan komputer.

Kata Kunci : Multimedia, Guru, Microsoft Power Point, Digital

\section{Latar Belakang Masalah}

Proses pembelajaran merupakan rangkaian beberapa sistem yang saling berkaitan satu sama lainnya. Apabila salah satu sistem tidak dapat berfungsi maka sistem tidak dapat bekerja secara optimal. Proses pembelajaran akan lebih optimal jika dapat memanfaatkan media yang ada di sekitar kita.Penggunaan media dalam proses pembelajaran diharapkan dapat membantu guru agar lebih mudah dalam mengajarkan materi kepada para siswa. Pembelajaran yang dilakukan selama ini cenderung kurang memanfaatkan media pembelajaran yang ada. Beberapa hal yang menyebabkan hal ini terjadi adalah masih adanya pandangan dari guru bahwa media pembelajaran merupakan sarana yang mahal dan sulit dibuat sendiri oleh guru. Salah satu media yang sering digunakan dalam proses pembelajaran di sekolah adalah media LKS (Lembar Kerja Siswa) dan diktat/modul pembelajaran. Oleh karena para guru pada umumnya memanfaatkan LKS atau diktat/modul pembelajaran yang diperoleh dari penerbit (bukan dibuat sendiri oleh guru) sehingga berakibat materi yang diberikan dalam LKS atau modul tersebut kurang sesuai dengan materi yang akan diajarkan oleh guru.

Kondisi di atas terjadi karena guru pada umumnya merasa kesulitan dalam mengembangkan media tersebut. Kemampuan guru dalam mengembangkan bahan ajar/diktat masih sangat rendah. Terdapat beberapa faktor yang menyebabkan hal ini terjadi, salah satunya masih minimnya penyelenggaraan pelatihan tentang pembuatan/pengembangan bahan ajar/diktat oleh instansi yang terkait. Peralihan kurikulum KBK ke kurikulum yang baru menuntut adanya kemampuan guru untuk dapat membuat dan mengembangkan sendiri bahan ajar maupun media yang sesuai dengan tingkat kompetensi yang ada di masing-masing sekolah. Pengembangan bahan ajar akan optimal jika Pembuat (pengembang) bahan ajar benar-benar mengetahui kondisi siswa yang akan menggunakan bahan ajar tersebut. Apabila kondisi ini dapat tercapai diharapkan siswa maupun guru akan lebih mudah berkolaborasi dalam mempelajari materi. Adanya kemampuan guru dalam mengembangkan bahan ajar secara tidak langsung akan meningkatkan life skill guru.

Oleh karena itu sangat penting untuk diselenggarakan kegiatan pengabdian pendampingan pembuatan bahan ajar berbasis multimedia menggunakan Microsoft Power Point. Selain karena adanya permintaan guru untuk diberikan bekal dalam memulai mengembangkan bahan ajar, juga karena keinginan untuk membantu para guru dalam mengembangkan bahan ajar. Kegiatan pengabdian ini berupa pendampingan dalam pembuatan bahan ajar berbasis multimedia menggunakan Microsoft Power Point bagi para guru di SDIT Salsabila Al Muthi’in Yogyakarta.

\section{Metodologi Pelaksanaan}

Kegiatan yang dilaksanakan berupa pendampingan dalam bentuk memberikan pelatihan penggunakan Microsoft Power Point untuk membuat bahan ajar yang berbasis mulimedia. Materi pelatihan disesuaikan dengan kebutuhan para guru agar dapat menjawab berbagai permasalahan yang menghambat pembuatan bahan ajar menggunakan aplikasi tersebut.

Pada tahapan pertama, tim pelaksanan pengabdian melakukan beberapa kegiatan, diantaranya koordinasi para pelaksana untuk menyiapkan tempat dan perlengkapan guna 
mendukung terlaksananya pelatihan, kemudian tim pelaksana melakukan koordinasi dengan para peserta yaitu guru SDIT Salsabilla Al Muthi' in untuk penyebaran undangan pelaksanaan pendampingan. Langkah berikutnya mempersiapkan modul pelatihan penggunaan Microsoft Power Point untuk membuat bahan ajar berbasis multimedia bagi guru dengan rincian materi seperti yang terlihat pada Tabel 1 .

Tabel 1. Topik Materi Pada Modul Pelatihan

\begin{tabular}{|c|l|}
\hline No. & \multicolumn{1}{|c|}{ Topik } \\
\hline 1. & Pengenalan Microsoft Power Point \\
\hline 2. & Bekerja dengan Daftar, Pemeriksaan Ejaan dan Naskah Ketikan \\
\hline 3. & Presentasi dengan Sound Movie dan Sound, Efek Animasi dalam Presentasi \\
\hline 4. & Tabel, Smart Art, Hyperlink, dan Action Button \\
\hline 5. & Penggunaan Slide Master, Penyimpanan Data dan Pencetakan Hasil \\
\hline
\end{tabular}

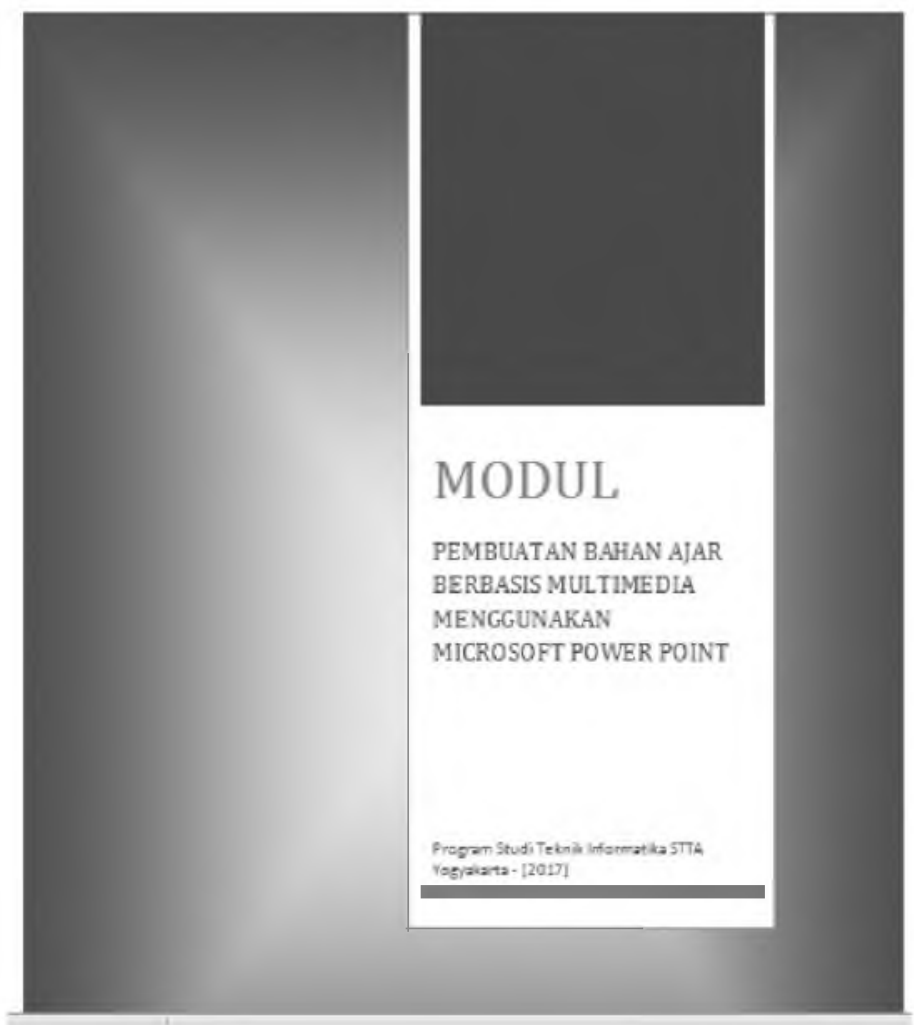

Gambar 1. Tampilan Cover Modul Pelatihan

Untuk mengukut tingkat keberhasilan kegiatan pendampingan pembuatan bahan ajar berbasis multimedia ini, peserta diberikan latihan untuk membuat bahan ajar sesuai dengan bidang yang diampunya masing-masing dalam bentuk softcopy berektensi .ppt. Tahap ini dimaksudkan untuk mengetahui kemampuan guru dalam memanfaatkan aplikasi yang diajarkan untuk membuat bahan ajar yang interaktif.

\section{Hasil dan Pembahasan}

Pendampingan pembuatan bahan ajar berbasis multimedia bagi Guru SDIT Salsabilla Al Muthi'in dengan menggunakan Microsoft Power Point dilaksanakan di Laboratorium Komputasi Sekolah Tinggi Teknologi Adisutjipto (STTA) Yogyakarta pada 14 dan 15 
Desember 2017 yang berlangsung pukul 08.00-13.00. Pendampingan dilaksanakan selama sepuluh jam, sesuai waktu yang ditargetkan. Pelaksana kegiatan terdiri dari lima orang dosen yang dibantu oleh tiga orang mahasiswa sebagai instruktur pelatihan.

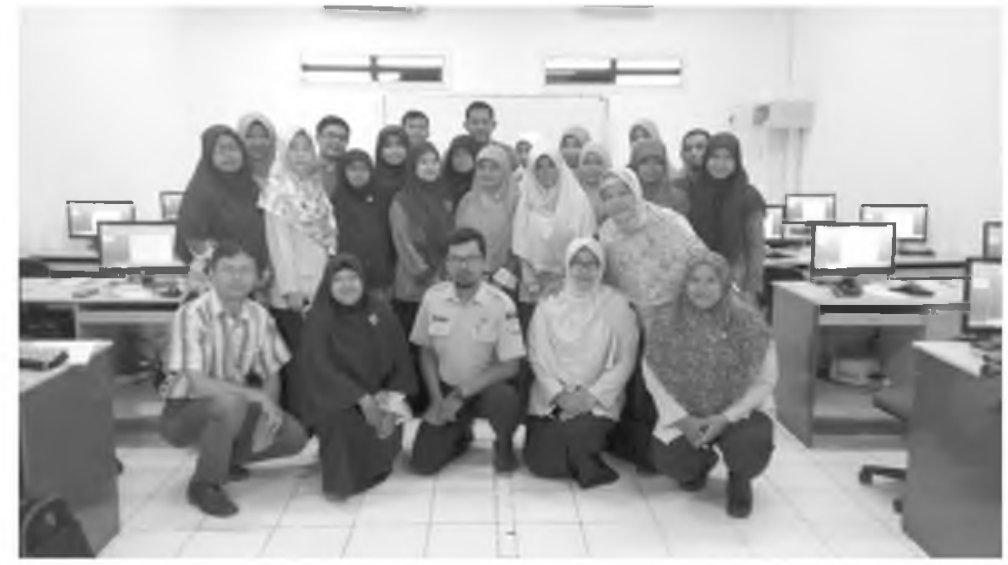

\section{Gambar 2. Tim Pelaksana dan Peserta Pengabdian Kepada Masyarakat Hari Pertama}

Jumlah peserta pengabdian secara keseluruhan adalah sembilan belas orang yang berasal dari SDIT Salsabilla Al Muthi' in Yogyakarta. Kesembilan belas tersebut merupakan delapan belas guru Sekolah Dasar (SD) yang mengampu beberapa mata pelajaran dan satu Kepala Sekolah SDIT Salsabila Al Muthi'in (Gambar 2 dan 3). Kegiatan diawali dengan pemberian sambutan oleh Kaprodi Teknik Informatika STTA Yogyakarta dan di hari terakhir pendampingan ditutup dengan pemberian kenang-kenangan dari Prodi Teknik Informatika STTA kepada SDIT Salsabilla Al Muthi' in (Gambar 4 dan 5)

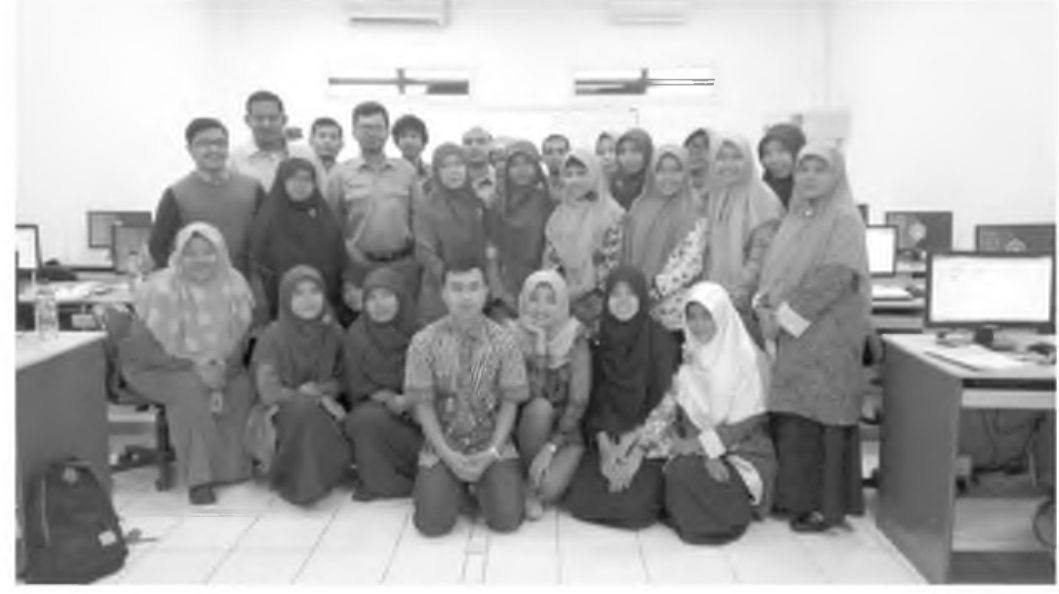

Gambar 3. Tim Pelaksana dan Peserta Pengabdian Kepada Masyarakat Hari Kedua

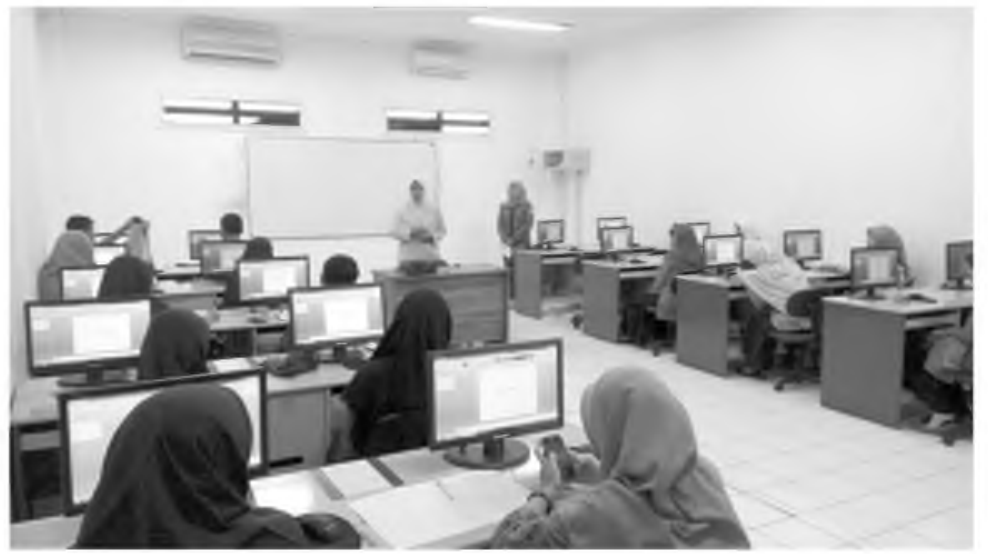

Gambar 4. Pembukan Kegiatan Pengabdian Kepada Masyarakat 


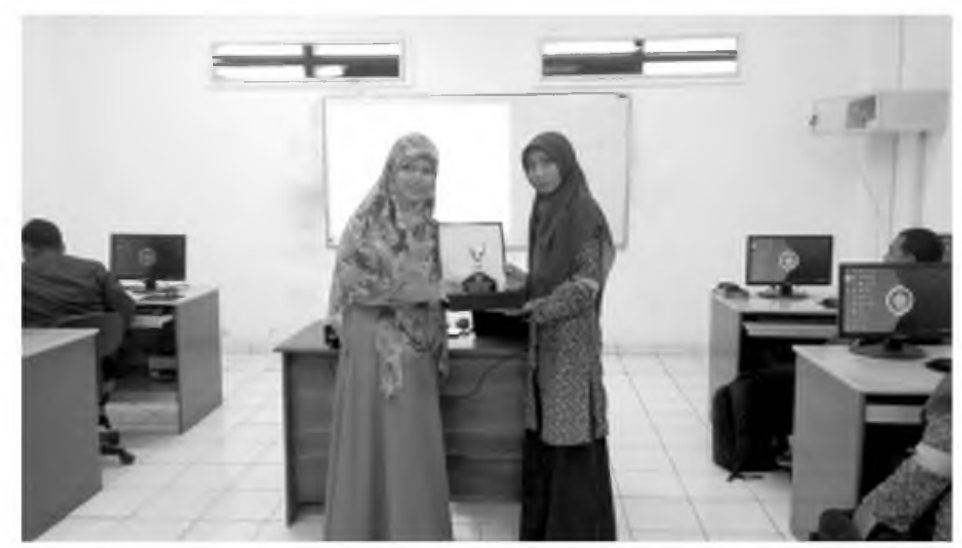

\section{Gambar 5. Penutupan Kegiatan Pengabdian Kepada Masyarakat}

Setelah materi pelatihan selesai, pada hari terakhir disediakan waktu kurang lebih sembilan puluh menit untuk para peserta mengerjakan latihan guna menguji pemahaman materi secara keseluruhan. Adapun setiap peserta diminta membuat bahan ajar sesuai dengan bidang yang diampunya masing-masing. Dari keseluruhan hasil yang dikumpulkan didapatkan rata-rata pemahaman peserta pada materi adalah $92 \%$ (dilihat dari hasil latihan .ppt yang dibuat). Salah satu contoh hasil pembuatan bahan ajar dapat dilihat pada Gambar 6 dan 7.
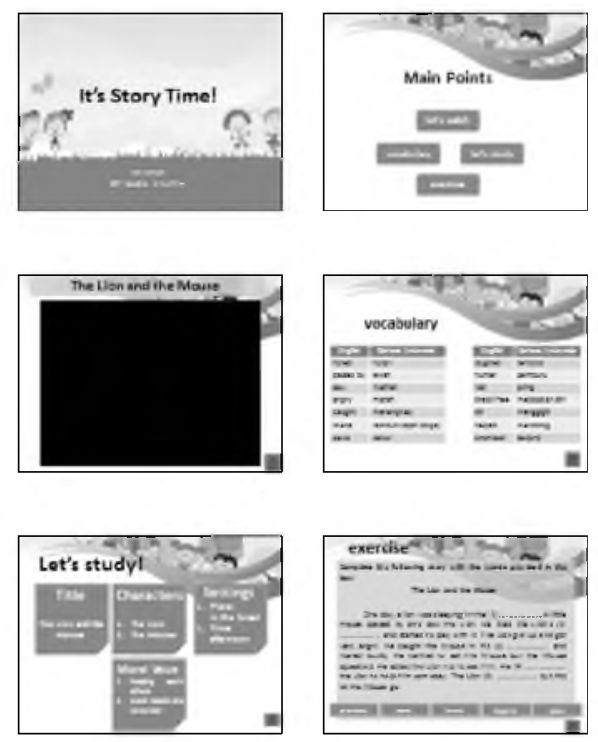

Gambar 6. Contoh Pertama Hasil Latihan Peserta 

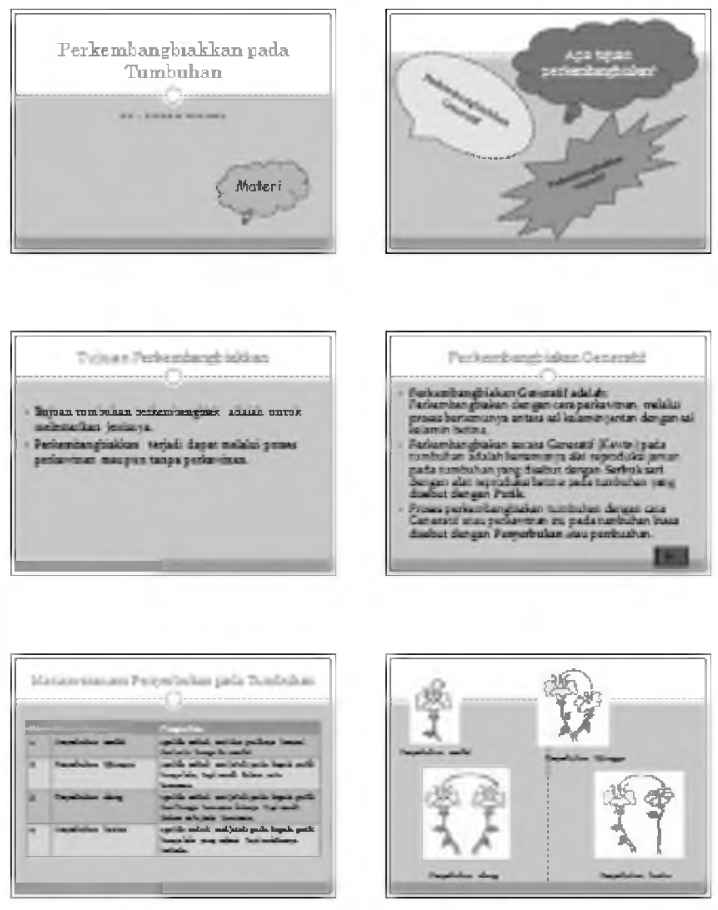

\section{Gambar 7. Contoh Kedua Hasil Latihan Peserta}

\section{Kesimpulan}

Kegiatan pengabdian kepada masyarakat berupa pendampingan pembuatan bahan ajar bagi guru SDIT Salsabilla Al Muthi'in Yogyakarta yang diselenggarakan oleh Dosen Program Studi Teknik Informatika STTA Yogyakarta mampu memberikan kontribusi positif terhadap peningkatan kemampuan para peserta (guru) dalam penggunaan Microsoft Power Point, khususnya untuk pembuatan bahan ajar yang interaktif. Untuk kedepannya perlu dikembangkan lagi keterampilannya dalam memanfaatkan teknolog informasi dan komputer pada contoh aplikasi yang lain, seperti Microsoft Word, Corel Draw, Macromedia Flash, sehingga terwujud peningkatan keterampilan yang dapat mendukung pembuatan bahan ajar bagi guru yang menarik untuk para siswanya.

\section{Daftar Pustaka}

[1] Christoper Lee, 2017, Belajar Microsoft PowerPoint (Mahir) Step-by-Step, Elex Gramedia

[2] Haer Talib, 2009. Panduan Praktis Belajar Komputer. Elex Media Komputindo. Jakarta.

[3] Tejo Nurseto, 2011, Membuat Media Pembelajaran yang Menarik, Jurnal ekonomi dan Pendidikan, Vol. 2, No. 1

[4] https://solution.office.com/, diakses pada tanggal 10 Desember 2017 